Perceived norms and alcohol use among first-year college student-athletes' different types of friends

By: Kelley E. C. Massengale, Alice Ma, Kelly L. Rulison, Jeffrey J. Milroy, and David L. $\underline{\text { Wyrick }}$

Massengale, K. E. C., Ma, A., Rulison, K., Milroy, J. \& Wyrick, D.L. (2017). Perceived norms and alcohol use among first-year college student-athletes' different types of friends. Journal of American College Health, 65(1) 32-40. https://doi.org/10.1080/07448481.2016.1233557

This is an Accepted Manuscript of an article published by Taylor \& Francis in Journal of American College Health on 01 November 2016, available online: http://www.tandfonline.com/10.1080/07448481.2016.1233557.

***@ 2017 Taylor \& Francis. Reprinted with permission. No further reproduction is authorized without written permission from Taylor \& Francis. This version of the document is not the version of record. ***

\begin{abstract}
:
Objective: To describe first-year college student-athletes' friendship contexts and test whether their perceptions of alcohol use and approval by different types of friends are associated with their own alcohol use. Participants: First-year student-athletes $(N=2,622)$ from 47 colleges and universities participating in National Collegiate Athletic Association (NCAA) sports during February-March 2013. Methods: Student-athletes completed online surveys during the baseline assessment of an alcohol and other drug prevention program evaluation. Analyses tested whether perceptions of friends' alcohol use (descriptive norms) and perceptions of friends' approval of alcohol use (injunctive norms) predicted their alcohol use. Results: Both use and approval perceptions by upperclassmen, same-team, and most influential friends significantly predicted alcohol use. By contrast, only perceived use by first-year, nonteam, and less influential friends significantly predicted alcohol use. Conclusions: Athletics departments' alcohol policies and prevention programming for first-year student-athletes should address the potential influence of different types of friends on alcohol use.
\end{abstract}

Keywords: Alcohol | friendships | social norms | student-athletes

Article:

Alcohol use is common among college student-athletes: in 2013, 81\% reported using alcohol in the past year, $44 \%$ of males and $33 \%$ of females reported heavy episodic drinking (ie, drinking $4+$ drinks in a row for females or $5+$ for males), and $18 \%$ of males and $3 \%$ of females reported extreme drinking (ie, drinking $10+$ in a row). ${ }^{1}$ As a result, the National Collegiate Athletic Association (NCAA) Sport Science Institute has stated that alcohol use continues to be the most important health and wellness issue facing their membership. ${ }^{2}$ Student-athletes have reported using alcohol as a coping mechanism for sports-related stress, as positive reinforcement for athletic performance, and to fit in with teammates. ${ }^{3}$ In other words, one reason for student- 
athletes' rates of alcohol use may be that they spend considerable time in sports-related activities, and thus with their peers. Peers shape alcohol use among adolescents and young adults in general, ${ }^{4-7}$ and among college student-athletes more specifically. ${ }^{8-10}$ For example, college students' perceptions of how much their peers drink (ie, descriptive norms) and how much their peers approve of alcohol use (ie, injunctive norms) are 2 of the most reliable predictors of college students' alcohol use. ${ }^{11-13}$ Therefore, clarifying how the friendship context shapes alcohol use among college student-athletes can improve prevention programs trying to reduce alcohol use among this at-risk population.

Despite the important role of peers in shaping alcohol use, little is known about college studentathletes' potentially unique peer context or how this peer context shapes their alcohol use. For instance, limited research exists on how much time college student-athletes spend in-person or online with their closest friends and whether most of their friends are similar to themselves. Therefore, the first goal of our present study was to describe the friendship context of first-year college student-athletes attending 47 different colleges and universities, focusing specifically on students who were not old enough to drink legally. In addition, despite evidence that adolescents are differentially influenced by different types of relationships (eg, close friends, group members, fraternity/sorority members), ${ }^{5,14,15}$ no studies have tested whether perceptions of different types of friends (eg, same-team vs nonteam, upperclassmen vs first-year) are differentially associated with alcohol use. Therefore, the second goal of our present study was to test the extent to which college student-athletes' perceptions of use and approval by different types of friends predicted their own current alcohol use.

\section{Peer context}

Peers often shape adolescents' and young adults' decisions around health behaviors, including food intake, ${ }^{16,17}$ sexual behaviors, ${ }^{18,19}$ and substance use ${ }^{4-6,14,20}$ College students spend considerable time interacting with their peers, and these peers in turn play a critical role in shaping students' identity during college. ${ }^{21,22}$ Peer influence can be a major factor in the initiation of risk-taking behaviors among young adults, ${ }^{23}$ including alcohol consumption. ${ }^{4,24,25}$

College student-athletes who believe that most of their friends use alcohol (ie, descriptive norms) and approve of alcohol-related behaviors (ie, injunctive norms) often have higher rates of alcohol use than others. ${ }^{8-10,26,27}$ Based upon the Theory of Normative Social Behavior, ${ }^{28}$ descriptive norms affect individuals' behaviors through 3 underlying normative mechanisms: injunctive norms (eg, social approval), outcome expectations (eg, benefits to self and others), and group identity (eg, similarity). Students' perceptions of how much their peers drink and their perceptions of how much their friends approve of drinking may both influence their behavior as they strive to fit in during social situations. ${ }^{29}$ Consistent with these ideas, the results of a normative alcohol intervention for college student-athletes demonstrated that sharing with student-athletes the actual campus rates of student-athletes' alcohol use and attitudes towards alcohol was associated with reductions in alcohol use and fewer negative consequences at 1month follow-up compared with baseline and further maintained at 2-month follow-up. ${ }^{30}$

There are several reasons to expect that the strength and amount of influence might vary among different types of friends. College student-athletes spend much of their time in sport-related 
activities (eg, practice, competition, strength and agility training) and, consequently, with their teammates. ${ }^{31,32}$ Typically, student-athletes place great emphasis on their athlete identity and sport participation, and thus may spend much of their time with their teammates and other studentathletes to further strengthen their athlete identity. ${ }^{32,33}$ Further, college student-athletes value the interpersonal and emotional relationships with their teammates ${ }^{31}$ and identify, on average, 4 of their 5 closest friends as other student-athletes. ${ }^{8}$ As a result, teammates and other student-athletes may have a stronger impact on college student-athletes' alcohol use than nonathletes. In addition, students in their first year of college may be influenced by the attitudes and behaviors of older peers, just as adolescents are influenced by older friends to use alcohol. ${ }^{34}$ For example, if they believe that their older peers are drinking a lot or approve of drinking, they may drink more to fit in or gain the approval of these older peers.

\section{Peer norms}

Perceived use by and approval from different types of peers can differentially contribute to college student-athletes' alcohol use. Yet only a few studies have examined the association between how much student-athletes think different types of friends approve of alcohol use and their own alcohol use. For instance, prior studies focused on teammates found that students who thought that their teammates approved of getting drunk ${ }^{35}$ or using alcohol ${ }^{10}$ were more likely to engage in risky drinking. Notably, however, these studies did not compare whether perceptions of teammates' drinking were stronger than perceptions of non-teammates' drinking. Another study found that student-athletes' perceptions of alcohol use by other athletes more strongly predicted their own alcohol use compared with their perceptions of alcohol use by nonathletes. ${ }^{8}$

\section{Present study}

Accordingly, the purpose of this study was twofold: (1) describe the friendship context of firstyear college student-athletes, and (2) test the extent to which first-year student-athletes' perceptions of their friends' alcohol use and their friends' approval of drinking are associated with their current alcohol use. We examined student-athletes' perceptions of different types of friends: first-year and upperclassmen friends, same-team and nonteam friends, and most influential and less influential friends. We hypothesized that perceptions of upperclassmen friends, same-team friends, and friends designated as most influential would be more strongly associated with student-athletes' current alcohol use than other types of friends.

The present study has multiple unique strengths. First, we focused on a large sample of first-year college student-athletes attending 47 colleges and universities across the United States. Second, we examined whether alcohol use could be differentially affected by different types of friends. Past studies about athletes and friendship norms have examined how much athletes believed their friends drink and/or approve of their alcohol use, ${ }^{9,36}$ but those studies did not elucidate how much the association between perceived friendship norms and athletes' alcohol use varies across different types of friends. Given that perceptions about friends are important predictors of behavior, ${ }^{8-10,26,27,29}$ it is particularly useful to compare perceptions about different types of friends on student-athletes' alcohol use (eg, first-year vs upperclassmen friends); our study design allowed us to tease apart the role of perceptions about individual friends. 


\section{Methods}

\section{Participants and procedures}

This paper uses data from the baseline assessment of a larger study that aimed to optimize and evaluate myPlaybook, an online alcohol and other drug prevention program designed for National Collegiate Athletic Association (NCAA) student-athletes. ${ }^{37,38}$ During a 3-week period from February to March 2013 and prior to accessing myPlaybook, student-athletes were invited to complete a Web-based baseline assessment of their friendship context and alcohol use behaviors. First-year student-athletes $(N=2,740)$ from 47 colleges and universities participated in the study. As alcohol use is illegal for young adults under the age of 21 years and our analyses focus on underage alcohol use as an outcome, we excluded 63 student-athletes who were age 21 years or older. We excluded 2 student-athletes who did not report their sex or in-season competition status. Lastly, we excluded 53 student-athletes who did not name any friends, resulting in a final analytic sample of 2,622.

Most student-athletes were either age $18(48 \%)$ or $19(48 \%)$ years. A higher percentage of student-athletes were from NCAA Division I schools (40.5\%) than either Division II (30.0\%) or Division III (29.5\%) schools. Student-athletes participated in 28 different sports, with soccer (14\%), football (11\%), and outdoor track and field (10\%) as the most commonly reported sports. Over half $(56 \%)$ of the sports were currently in season. Approximately equal percentages of male $(47 \%)$ and female (53\%) student-athletes participated. Most student-athletes identified as White/Caucasian (81\%), with another 11\% identifying as Black/African American and 8\% identifying as another race or 2 or more races; $8 \%$ of all student-athletes identified as Hispanic or Latino.

The institutional review board at the University of North Carolina at Greensboro approved study protocols. All student-athletes provided informed consent electronically prior to completing the survey.

\section{Data analysis}

We used descriptive statistics to describe student-athletes' friendship context. Then, we used paired-samples $t$-tests to test differences between types of friends in the amount of time spent with friends, student-athletes' perceptions about friends' alcohol use, and student-athletes' perceptions about friends' approval of alcohol use. Next, we conducted a series of multiple linear regression analyses to test the relationships between student-athletes' perceptions of friends' alcohol use and approval and student-athletes' current alcohol use. In the regression analyses, we controlled for multiple demographic (eg, sex, race) and athletic team (eg, athletic season, NCAA division) variables that might be associated with alcohol use. We assumed that student-athletes who were missing a particular type of friend (eg, they did not identify any same-team friends) did not have that type of friend among their closest friends. Therefore, we excluded from the analysis student-athletes who did not have both types of friends being compared, and we did not use any missing data approaches to include them. All statistical analyses were performed using SPSS. ${ }^{39}$ 
Measures

Friendship types and characteristics

Student-athletes listed the first names or initials of up to 5 of their closest friends who also attended the same college or university and answered a series of questions about each of these friends. For each question, student-athletes saw the names or initials of the friends they had identified.

Types of friends

We categorized types of friends based on 3 dimensions: year in school, athlete status, and most influential friend. First, student-athletes identified each friend's year in school (1st year [freshman], 2nd year or higher, graduate students), which we recoded into first-year versus upperclassmen. Second, student-athletes indicated whether each friend was a student-athlete (yes [on my team], yes [on a different team], no), which we recoded into same-team versus nonteam friends. Third, student-athletes identified which of these 5 friends they considered to be the most influential, which we recoded into most influential versus less influential friends.

Time with friends

Student-athletes indicated the total hours in the past 7 days that they spent interacting with each friend in-person (not counting time spent together in class or practice) and electronically (eg, texting, Facebook, Twitter, or e-mail): none, less than 1 hour, 1-3 hours, 4-7 hours, or 8 or more hours. We recoded time spent in-person and online at the midpoints of the intervals and computed the average number of hours across different types of friends (eg, same-team vs nonteam friends).

Number of close friends

In addition to the up to 5 close friends they listed by name or initials, student-athletes answered 2 open-ended questions: one about the total number of other close friends they had at their same college or university and one about the total number of close friends they had who did not attend their same college or university. To calculate total number of close friends from the school, we added the number of close friends identified by name or with initials to the total number of other close friends from the same school. To calculate each student-athlete's total number of close friends, we added total number of close friends from the same school and the total number of close friends from outside of school.

Perceived use

To measure student-athletes' perceptions of friends' alcohol use, student-athletes indicated, on average, how many drinks of alcohol they thought each friend usually consumed per occasion: does not drink, less than 1 drink, 1 drink, 2-3 drinks, 4-5 drinks, or 6 or more drinks. We recoded the amount of alcohol consumed by friends at the midpoints. 


\section{Perceived approval}

To measure student-athletes' perceptions of friends' approval of heavy episodic drinking, studentathletes indicated the degree to which each of their friends would approve of them drinking 5 or more drinks on 1 occasion $(1=$ strongly disapprove to $5=$ strongly approve $)$.

Student-athletes' alcohol use

To determine current alcohol use, student-athletes reported how many days within the past 30 days they had consumed alcohol: 0 days, 1 day, 2 days, 3-5 days, 6-9 days, or 10 or more days. For answer choices that contained ranges, we recoded the amount of alcohol consumed at the midpoints.

\section{Results}

Friendship context

Student-athletes were in their first year of eligibility, yet they had already established clear friendship networks with other students at their college or university. Almost all students in the sample (96\%) named 5 friends, the maximum allowed. The median total number of close friends from the same school was 10 friends (range $=1-105$ ). Still, student-athletes had connections with many friends who were not at the same school: the median total number of close friends was 17 (range $=1-205)$.

When asked to describe their 5 closest friends, student-athletes most often described these friends as similar to themselves. Like the student-athletes themselves, most friends were also first-year students rather than upperclassmen $(M=3.8, S D=1.4$ vs $M=1.2, S D=1.4, t=$ $47.66, p<.001)$. In fact, almost half of all student-athletes $(46.8 \%)$ named only friends who were also first-year students (compared with only $2.9 \%$ who named only upperclassmen friends). Student-athletes also had more same-team friends than nonteam friends $(M=3.0, S D=$ 1.7 vs $M=2.0, S D=1.6, t=15.55, p<.001)$. Although more students had nonteam friends than upperclassmen friends, twice as many students named only same-team friends $(26.1 \%)$ as those who named only nonteam friends (10.8\%). Most influential friends were also similar to the student-athletes: the majority were first-year students $(71.6 \%)$ and on the same team as the student-athletes $(63.2 \%)$.

Time spent with friends

On average, student-athletes spent approximately 5 hours per week in-person with each of their friends and just under 2 hours a week communicating online with each of them. As shown in Table 1, student-athletes spent significantly more time in-person, but less time online, with their friends who were most like themselves (ie, other first-year student-athletes; same-team friends). Student-athletes reported spending more time both in-person and communicating online with their most influential friends compared with their noninfluential friends. 
Table 1. Paired t-test comparisons of different types of friends' characteristics.

\begin{tabular}{|c|c|c|c|c|c|c|c|c|c|c|c|c|c|c|c|}
\hline \multirow[b]{2}{*}{ Characteristic } & \multicolumn{2}{|c|}{ Same-team } & \multicolumn{2}{|c|}{ Nonteam } & \multirow[b]{2}{*}{$\mathbf{t}$} & \multicolumn{2}{|c|}{ First-year } & \multicolumn{2}{|c|}{ Upperclassmen } & \multirow[b]{2}{*}{$\mathbf{t}$} & \multicolumn{2}{|c|}{$\begin{array}{c}\text { Most } \\
\text { influential }\end{array}$} & \multicolumn{2}{|c|}{$\begin{array}{c}\text { Less } \\
\text { influential }\end{array}$} & \multirow[b]{2}{*}{ t } \\
\hline & Mean & SD & Mean & SD & & Mean & SD & Mean & SD & & Mean & SD & Mean & SD & \\
\hline Hours spent in-person & 5.20 & 2.49 & 4.67 & 2.63 & $7.02^{* * * *}$ & 4.97 & 2.42 & 4.42 & 2.66 & $7.39^{* * *}$ & 5.82 & 2.74 & 4.69 & 2.33 & $23.42^{* * *}$ \\
\hline Hours spent online & 1.71 & 2.07 & 1.93 & 2.28 & $4.59^{* * *}$ & 1.79 & 2.05 & 1.91 & 2.27 & $2.58^{*}$ & 2.30 & 2.63 & 1.59 & 1.91 & $19.22^{* * *}$ \\
\hline Perceived use & 2.35 & 1.93 & 2.57 & 2.00 & $5.36^{* * *}$ & 2.15 & 1.90 & 2.34 & 2.03 & $4.56^{* * *}$ & 2.21 & 2.18 & 2.46 & 1.87 & $8.21^{* * *}$ \\
\hline Perceived approval & 2.40 & 1.18 & 2.48 & 1.19 & $4.19^{* * *}$ & 2.38 & 1.17 & 2.38 & 1.21 & 0.16 & 2.32 & 1.27 & 2.47 & 1.17 & $10.97^{* * *}$ \\
\hline n $(\text { range })^{\mathrm{a}}$ & & & $1610-1$ & & & & & $1274-12$ & & & & & $2497-25$ & 533 & \\
\hline
\end{tabular}

Note. ${ }^{a}$ Paired $t$-test analyses for everything except number of close friends, which only included students who listed at least 1 friend of each type. Therefore, the sample size for each analysis differed, depending on how many students had both types of friends being considered. The sample size for each of the number of close friends analyses was $N=2,622$.

$* p<.05 ; * * * p<.001$.

Comparisons of friends' perceived alcohol use

Friends most similar to the student-athletes (ie, other first-year student-athletes; same-team friends) were perceived by student-athletes to drink a little less on average than their nonteam and upperclassmen friends (see Table 1). In terms of perceptions of friends' approval of alcohol use, same-team friends $(M=2.40, S D=1.18)$ were perceived by student-athletes as slightly less likely to approve of their drinking compared with nonteam friends $(M=2.48, S D=1.19)$, but there were no mean differences in perceived approval between upperclassmen $(M=2.38, S D=$ $1.21)$ and first-year friends $(M=2.38, S D=1.17)$. Student-athletes also perceived that their most influential friends both drank less and were less likely to approve of their drinking compared with their less influential friends.

Testing the link between perceived use, perceived approval, and student-athletes' alcohol use

As previously described, student-athletes who did not have both types of friends being compared were excluded from the corresponding regression analyses. Thus, analyses for year in school included only $50.3 \%$ of student-athletes, and analyses for team status included only $63.1 \%$ of student-athletes. Almost everyone identified both an influential friend and other friends, so analyses for influential friends included $99.2 \%$ of student-athletes.

Perceived use and perceived approval

\section{All friends}

When considering all named friends, both perceptions about alcohol use and perceptions of friends' approval were significantly associated with student-athletes' current alcohol use: studentathletes who perceived their friends as drinking more and approving of their drinking were more likely to drink (see Table 2). Notably, the standardized regression coefficient for perceived use ( $\beta$ $=.391, p<.001)$ was larger than the standardized regression coefficient for perceived approval $(\beta$ $=.181, p<.001)$. 
Table 2. Regression analysis for student-athletes' perceptions of friends' alcohol use and approval of use predicting student-athletes' current alcohol use.

\begin{tabular}{|c|c|c|c|c|c|c|c|c|}
\hline \multirow{2}{*}{ Variable } & \multicolumn{2}{|c|}{ All friends } & \multicolumn{2}{|c|}{ Year in school } & \multicolumn{2}{|c|}{ Team status } & \multicolumn{2}{|c|}{ Influence } \\
\hline & $\beta$ & $p$ & $\beta$ & $p$ & $\beta$ & $p$ & $\beta$ & $p$ \\
\hline \multicolumn{9}{|l|}{ All friends } \\
\hline Perceived use & .391 & $.000^{* * *}$ & & & & & & \\
\hline Perceived approval & .181 & $.000^{* * *}$ & & & & & & \\
\hline \multicolumn{9}{|l|}{ First-year } \\
\hline Perceived use & & & .239 & $.000^{* * *}$ & & & & \\
\hline Perceived approval & & & .034 & .516 & & & & \\
\hline \multicolumn{9}{|l|}{ Upperclassmen } \\
\hline Perceived use & & & .109 & $.008^{* *}$ & & & & \\
\hline Perceived approval & & & .208 & $.000^{* * *}$ & & & & \\
\hline \multicolumn{9}{|l|}{ Same-team } \\
\hline Perceived use & & & & & .226 & $.000^{* * *}$ & & \\
\hline Perceived approval & & & & & .131 & $.002^{* *}$ & & \\
\hline \multicolumn{9}{|l|}{ Nonteam } \\
\hline Perceived use & & & & & .176 & $.000^{* * *}$ & & \\
\hline Perceived approval & & & & & .082 & .059 & & \\
\hline \multicolumn{9}{|l|}{ Influential } \\
\hline Perceived use & & & & & & & .176 & $.000^{* * *}$ \\
\hline Perceived approval & & & & & & & .167 & $.000^{* * *}$ \\
\hline \multicolumn{9}{|l|}{ Less influential } \\
\hline Perceived use & & & & & & & .227 & $.000^{* * *}$ \\
\hline Perceived approval & & & & & & & .046 & .216 \\
\hline \multicolumn{9}{|l|}{ Controls } \\
\hline Out of season & .101 & $.000^{* * *}$ & .131 & $.000^{* * *}$ & .100 & $.000^{* * *}$ & .102 & $.000^{* * *}$ \\
\hline Female & -.011 & .562 & .017 & .474 & -.013 & .556 & -.016 & .338 \\
\hline Black race & -.036 & $.041^{*}$ & -.050 & $.047^{*}$ & -.041 & .059 & -.036 & $.042^{*}$ \\
\hline Other race & -.007 & .681 & .005 & .836 & -.001 & .973 & -.008 & .628 \\
\hline Division 2 & .003 & .882 & -.009 & .836 & -.002 & .922 & .003 & .859 \\
\hline Division 3 & .032 & .090 & .018 & .721 & .020 & .413 & .037 & .051 \\
\hline $\mathrm{R}^{2}$ & .301 & & .303 & & .299 & & .317 & \\
\hline
\end{tabular}

Note. Season was coded as $0=$ In season, $1=$ Out of season; Sex was coded as $0=$ Male, Female $=1$; Black race was coded as $0=$ White or Other race, $1=$ Black; Other race was coded as $0=$ White or Black, $1=$ Other race; Division 2 was coded as $0=$ Division 1 or $3,1=$ Division 2; Division 3 was coded as $0=$ Division 1 or $1,1=$ Division 3.

$* p<.05 ; * * p<.01 ; * * * p<.001$.

First-year versus upperclassmen friends

Only student-athletes' perceived use by first-year friends was significantly associated with student-athletes' current alcohol use $(\beta=.239, p<.001)$. In contrast, both perceived use ( $\beta$ $=.109, p=.008)$ and perceived approval $(\beta=.208, p<.001)$ by upperclassmen friends were significantly associated with current student-athletes' alcohol use, with a larger standardized regression coefficient for perceived approval.

Same-team versus nonteam friends

Both perceived use $(\beta=.226, p<.001)$ and perceived approval $(\beta=.131, p=.002)$ by same-team friends were significantly associated with current student-athletes' alcohol use, although the 
standardized regression coefficient for perceived use was larger. In contrast, only perceived use by nonteam friends was significantly associated with current alcohol use $(\beta=.176, p<.001)$.

Influential versus less influential friends

Both perceived use $(\beta=.176, p<.001)$ and perceived approval $(\beta=.167, p<.001)$ by most influential friends were significantly associated with student-athletes' current alcohol use. In contrast, only perceived use by less influential friends was significantly associated with studentathletes' current alcohol use $(\beta=.227, p<.001)$.

\section{Comment}

The first goal of our study was to describe the friendship contexts of a sample of first-year student-athletes from 47 colleges and universities. We found that among their closest friends at their school, first-year student-athletes primarily identified friends who were similar to themselves (ie, most were also first-year student-athletes and on the same team). Student-athletes also spent more time in-person with friends most similar to themselves compared with friends who were not on their same team or were upperclassmen. When apart from friends and teammates, college student-athletes maintain virtual contact via online social networking sites. ${ }^{40}$ As a result of increased monitoring of college student-athletes' use of online social networking sites, ${ }^{41}$ text messaging presents another medium for communication within personal relationships. Given the rapid increase in opportunities for socializing online (eg, online social networking sites; chat functions; social media applications), one might suspect that young adults are starting to spend more time interacting with their friends online rather than in-person. Our results, however, indicate that the opposite is true: student-athletes spent over 2.5 times more time in-person with their friends compared with the time spent online with them. Although the student-athletes in our study spent more time in-person with their friends, the mutual time spent online may not be unimportant, as what students see online contributes to their development of norms and can impact their alcohol use. For example, previous studies have demonstrated a link between the alcohol use descriptive norms adolescents encounter online and their attitudes toward alcohol, ${ }^{42,43}$ as well as their own alcohol use. ${ }^{44}$

The second goal of our study was to test whether student-athletes' perceptions of friends' alcohol use and perceptions of friends' approval of alcohol use were related to their own alcohol use. Consistent with past studies, we found that both how much student-athletes thought their closest friends drank (ie, descriptive norms) and perceived peer approval from their closest friends (ie, injunctive norms) were related to student-athletes' alcohol use. ${ }^{8-10,26,27}$ Notably, however, student-athletes' perceptions of their friends' alcohol use had a larger association with studentathletes' current alcohol use than student-athletes' perceptions of their friends' approval of alcohol use.

One strength of our study is that we collected data from student-athletes about their individual friends, which allowed us to identify important differences across types of friends. When we analyzed perceived use and perceived approval within subsets of friends, we found that associations with student-athletes' current alcohol use differed across types of friends. Perceived approval by upperclassmen friends, for example, had a larger association than perceived use by 
these friends, differing from the patterns noted when looking at all close friends. Comparing standardized beta values from the regression analyses across categories of friends, perceived use by first-year friends had the greatest association with student-athletes' current alcohol use. In addition, our comparison of the standardized betas of the perceived use by same-team friends compared with nonteam friends supports social norms theory, which indicates that the more proximal the norm, the greater the effect of the norm on behavior. ${ }^{45}$

The alcohol use behaviors that student-athletes perceived were modeled by same-team friends, first-year students, and less influential friends and may set an example for student-athletes on what alcohol use behaviors would allow them to fit in with peers most similar to themselves. Yet dissimilar peers may also be important. As the perceived approval by upperclassmen was a particularly strong predictor of student-athletes' current alcohol use, program developers may want to create interventions that use upperclassmen as opinion leaders to diffuse more appropriate alcohol use norms. Such strategies have been used successfully to reduce tobacco use intentions among adolescents. ${ }^{46}$ Alcohol use reduction programming specifically targeting the natural leadership capabilities of upperclassmen student-athletes may be effective, as the upperclassmen on an athletic team convey to the first-year students joining the team what alcohol use attitudes are acceptable for the team. In addition, programs targeting teams collectively to discuss how teammates' alcohol use and heavy episodic drinking can affect the entire team may appeal to first-year student-athletes seeking approval of upperclassmen on the team.

\section{Limitations}

This study was cross-sectional; thus, we could not study whether changes in perceived use and perceived approval were associated with changes in alcohol use. Whereas our study measured student-athletes' alcohol use and their perceptions of their friends' use and approval at one time point only, different types of norms may better predict current versus future alcohol use. Our results identified a larger link between perceived use and student-athletes' current alcohol use compared with perceived approval. However, previous research found that whereas descriptive norms were the best predictor of college fraternity and sorority members' current alcohol use, injunctive norms were the best predictor of their future alcohol use behaviors. ${ }^{14}$ The norms variables in our model account for $30 \%$ of the variance; the portion that is unexplained could be accounted for by other predictors of alcohol use (eg, outcome expectancies, motives for drinking), as well as other characteristics of friends, such as the amount of time spent with friends (in-person and online) and digital exposure to alcohol via social media.

\section{Future directions}

As student-athletes in our study entered only the first names or initials of their friends, we could not determine whether their friends were also enrolled in the study or use friends' reports of their own behaviors. Therefore, we could only test the role of student-athletes' perceptions of friends' alcohol use and perceptions of friends' approval of alcohol use on student-athletes' behaviors and not the role of friends' actual behaviors. Our results suggest that future studies of student-athletes' friendships could collect network data from all first-year students at a college or university to allow researchers to develop a more complete picture from which to evaluate possible connections among specific characteristics of student-athletes' friends, friends' actual behaviors, 
alcohol use norms, and alcohol use. Future studies should also examine the role of different types of peers in the development of other behaviors, such as sexual risk behaviors and other negative alcohol-related consequences, to determine the mechanisms by which peers, perceived norms, and risky behaviors are interrelated among college student-athletes.

Conclusions

This study describes the friendship context among first-year college student-athletes. Our results indicated that student-athletes have friends who are similar to themselves (ie, also first-year student-athletes and on their same team) and spend more time interacting with their friends inperson than online. Because so many of their friends are other first-year students, our findings suggest that a comprehensive depiction of first-year student-athletes' friendships could be obtained by collecting data suitable for social network analysis from all first-year students at a college or university. Furthermore, prevention programming aimed at reducing alcohol use among student-athletes should consider the potential influence from different types of friends on alcohol use by involving different types of peers (eg, upperclassmen on the same athletic team) as leaders during program delivery. Finally, this paper presents the foundation for investigating further the roles social norms from different types of friends play in influencing other risk behaviors of college student-athletes.

\section{Conflict of interest disclosure}

The authors have no conflicts of interest to report. The authors confirm that the research presented in this article met the ethical guidelines, including adherence to the legal requirements, of the United States and received approval from the Institutional Review Board of the University of North Carolina at Greensboro.

\section{Funding}

A grant from the National Institute on Drug Abuse (NIDA; R44 DA023735-02A2) provided funding to collect the data analyzed in this study.

\section{References}

1. The National Collegiate Athletic Association. National study of substance use habits of college student-athletes.

http://www.ncaa.org/sites/default/files/Substance\%20Use\%20Final\%20Report_FINAL.pdf Updated August 2013. Accessed April 15, 2016.

2. The National Collegiate Athletic Association Sport Science Institute. Implementing best practices to support key student-athlete health and safety initiatives. Workshop presented at 2016 NCAA Convention; January 14-16, 2016; San Antonio, Texas. https://www.ncaa.org/sites/default/files/2016Con_SSI-Workshop_20160204.pdf Updated January 2016. Accessed April 18, 2016. 
3. Martens MP, Martin JL. College athletes' drinking motives and competitive seasonal status: additional examination of the athlete drinking scale. Addict Res Theory. 2010;18:23-32.

4. Borsari B, Carey KB. Peer influences on college drinking: a review of the research. J Subst Abuse. 2001;13:391-424.

5. Rulison KL, Patrick ME, Maggs J. Linking peer relationships to substance use across adolescence. In: Brown S, Zucker RA, eds. The Oxford Handbook of Adolescent Substance Abuse. New York, NY: Oxford Press; 2015. doi: 10.1093/oxfordhb/9780199735662.013.019.

6. Patrick ME, Schulenberg JE, O'Malley PM, et al. Age-related changes in reasons for using alcohol and marijuana from ages 18 to 30 in a national sample. Psychol Addict Behav. 2011;25:330-339.

7. Huang GC, Soto D, Fujimoto K, et al. The interplay of friendship networks and social networking sites: longitudinal analysis of selection and influence effects on adolescent smoking and alcohol use. Am J Public Health. 2014;104: e51-e59.

8. Dams-O'Connor K, Martin JL, Martens MP. Social norms and alcohol consumption among intercollegiate athletes: the role of athlete and nonathlete reference groups. Addict Behav. 2007;32:2657-2666.

9. Grossbard J, Geisner IM, Neighbors C, Kilmer JR, Larimer ME. Are drinking games sports? College athlete participation in drinking games and alcohol-related problems. J Stud Alcohol Drugs. 2007;68:97-105.

10. Olthuis JV, Zamboanga BL, Martens MP, Ham LS. Social influences, alcohol expectancies, and hazardous alcohol use among college athletes. J Clin Sport Psychol. 2011;5:24-43.

11. Neighbors C, Lee CM, Lewis MA, Fossos N, Larimer ME. Are social norms the best predictor of outcomes among heavy-drinking college students? J Stud Alcohol Drugs. 2007;68:556-565.

12. Neighbors C, O'Connor RM, Lewis MA, et al. The relative impact of injunctive norms on college student drinking: the role of reference group. Psychol Addict Behav. 2008;22:576-581.

13. Lorant V, Nicaise P, Soto VE, d'Hoore W. Alcohol drinking among college students: college responsibility for personal troubles. BMC Public Health. 2013;13:615. doi: 10.1186/1471-2458$13-615$.

14. Larimer ME, Turner AP, Mallett KA, Geisner IM. Predicting drinking behavior and alcoholrelated problems among fraternity and sorority members: examining the role of descriptive and injunctive norms. Psychol Addict Behav. 2004;18:203-212. 
15. Rodriguez LM, Young CM, Tomkins MM, Dibello AM, Krieger H, Neighbors C. Friends in low places: the impact of locations and companions on 21 st birthday drinking. Addict Behav. 2016;52:52-57.

16. Cruwys T, Bevelander KE, Hermans RC. Social modeling of eating: a review of when and why social influence affects food intake and choice. Appetite. 2015;86:3-18.

17. Salvy S, De La Haye K, Bowker JC, Hermans RC. Influence of peers and friends on children's and adolescents' eating and activity behaviors. Physiol Behav. 2012;106:369-378.

18. Coley RL, Lombardi CM, Lynch AD, Mahalik JR, Sims J. Sexual partner accumulation from adolescence through early adulthood: the role of family, peer, and school social norms. J Adolesc Health. 2013;53:91-97.e2.

19. van de Bongardt D, Reitz E, Sandfort T, Dekovic M. A meta-analysis of the relations between three types of peer norms and adolescent sexual behavior. Pers Soc Psychol Rev. 2015;19:203-234. doi: 10.1177/1088868314544223.

20. Kiuru N, Burk WJ, Laursen B, Salmela-Aro K, Nurmi J. Pressure to drink but not to smoke: disentangling selection and socialization in adolescent peer networks and peer groups. J Adolesc. 2010;33:801-812.

21. Schulenberg JE, Maggs JL. A developmental perspective on alcohol use and heavy drinking during adolescence and the transition to young adulthood. J Stud Alcohol. 2002: (Suppl 14):5470 .

22. Teese R, Bradley G. Predicting recklessness in emerging adults: a test of a psychosocial model. J Soc Psychol. 2008;148:105-128.

23. Reniers RL, Beavan A, Keogan L, Furneaux A, Mayhew S, Wood SJ. Is it all in the reward? Peers influence risk-taking behaviour in young adulthood. Br J Psychol. 2016 [Epub ahead of print]. doi:10.111/bjop.12195

24. Borsari B, Murphy JG, Barnett NP. Predictors of alcohol use during the first year of college: implications for prevention. Addict Behav. 2007;32:2062-2086.

25. Osgood DW, Ragan DT,Wallace L, et al. Peers and the emergence of alcohol use: influence and selection processes in adolescent friendship networks. J Res Adolesc. 2013;23:500-512.

26. Martens MP, Dams-O'Connor K, Beck NC. A systematic review of college student-athlete drinking: prevalence rates, sport-related factors, and interventions. J Subst Abuse Treat. 2006;31:305-316.

27. Turrisi R, Mastroleo NR, Mallett KA, Larimer ME, Kilmer JR. Examination of the mediational influences of peer norms, environmental influences, and parent communications on heavy drinking in athletes and nonathletes. Psychol Addict Behav. 2007;21:453-461. 
28. Rimal RN, Real K. How behaviors are influenced by perceived norms a test of the theory of normative social behavior. Commun Res. 2005;32:389-414.

29. Rimal RN, Lapinski MK. A re-explication of social norms, ten years later. Commun Theory. 2015;25:393-409.

30. LaBrie JW, Hummer JF, Huchting KK, Neighbors C. A brief live interactive normative group intervention using wireless keypads to reduce drinking and alcohol consequences in college student athletes. Drug Alcohol Rev. 2009;28:40-47.

31. Schrack-Walters A, O'Donnell KA, Wardlow DL. Deconstructing the myth of the monolithic male athlete: a qualitative study of men's participation in athletics. Sex Roles. 2009;60:81-99.

32. Potuto JR, O'Hanlon J. National study of student-athletes regarding their experiences as college students. Coll Stud J. 2007;41:947-966.

33. Chen S, Snyder S, Magner M. The effects of sport participation on student-athletes' and nonathlete students' social life and identity. J Issues Intercoll Athletics. 2010;3:176-193.

34. Bremner P, Burnet J, Nunney F, Ravat M, Mistral W. Young people, alcohol and influences. Joseph Rowntree Foundation. https://www.jrf.org.uk/report/young-people-alcohol-andinfluences. Updated June 2011. Accessed April 15, 2016.

35. Williams RD Jr, Perko MA, Usdan SL, Leeper JD, Belcher D, Leaver-Dunn DD. Influences on alcohol use among NCAA athletes: application of the social ecology model. Am J Health Stud. 2008;23:151-159.

36. Woolf J, Rimal RN, Sripad P. Understanding the influence of proximal networks on high school athletes' intentions to use androgenic anabolic steroids. J Sport Manage. 2014;28:8-20.

37. Wyrick DL, Rulison KL, Fearnow-Kenney M, Milroy JJ, Collins LM. Moving beyond the treatment package approach to developing behavioral interventions: addressing questions that arose during an application of the multiphase optimization strategy (MOST). Transl Behav Med. 2014;4:252-259.

38. Milroy JJ, Orsini MM, Wyrick DL, Fearnow-Kenney M, Wagoner KG, Caldwell R. Implementing an alcohol and other drug use prevention program using University-High school partnerships: challenges and lessons learned. Am J Health Educ. 2015;46:310-313.

39. SPSS [computer program]. Version 22. Armonk, NY: IBM Corporation; 2013.

40. Browning B, Sanderson J. The positives and negatives of twitter: exploring how studentathletes use twitter and respond to critical tweets. Int J Sport Commun. 2012;5:503-521. 
41. Hopkins JP, Hopkins K, Whelton B. Being social: why the NCAA has forced universities to monitor student-athletes' social media. Univ Pittsburgh J Technol Law Policy. 2013;13:1-45.

42. Moreno MA, Briner LR, Williams A, Walker L, Christakis DA. Real use or "real cool": adolescents speak out about displayed alcohol references on social networking websites. J Adolesc Health. 2009;45:420-422.

43. Boyle SC, LaBrie JW, Froidevaux NM, Witkovic YD. Different digital paths to the keg? how exposure to peers' alcohol-related social media content influences drinking among male and female first-year college students. Addict Behav. 2016;57:21-29.

44. Litt DM, Stock ML. Adolescent alcohol-related risk cognitions: the roles of social norms and social networking sites. Psychol Addict Behav. 2011;25:708-713.

45. Berkowitz AD. Applications of social norms theory to other health and social justice issues. In: Perkins HW, eds. The Social Norms Approach to Preventing School and College Age Substance Abuse: A Handbook for Educators, Counselors, and Clinicians. San Francisco, CA: Jossey-Bass; 2003:259-279.

46. Valente TW, Hoffman BR, Ritt-Olson A, Lichtman K, Johnson CA. Effects of a socialnetwork method for group assignment strategies on peer-led tobacco prevention programs in schools. Am J Public Health. 2003;93:1837-1843. 